\title{
Resilience Processes in Children with Leukemia: Developing a New
}

\section{Resilience Model}

\section{Kyoko Nakazawa ${ }^{1}$ and Ikuko Sobue ${ }^{2^{*}}$}

${ }^{1}$ Faculty of Nursing, Shikoku University, Furukawa, Ojin-cho, Tokushima-shi, 771-1192, Japan

${ }^{2}$ Division of Nursing Science, Graduate School of Biomedical \& Health Sciences, Hiroshima University, 1-2-3, Kasumi, Minami-ku, Hiroshima 734-8553, Japan

\begin{abstract}
Background: To clarify the details of resilience processes in children with leukemia who repeatedly undergo examination and treatment, with the aim of providing a basis for the prevention of posttraumatic stress disorder in such children.

Methods: A qualitative study based on the hybrid model of concept development. To demonstrate that resilience processes have been exclusively examined in theoretical studies in the theoretical phase, and clarify the details of such processes in the fieldwork phase, semi-structured interviews regarding examination and treatment were conducted with 7 children (aged 9 to 15 years) with leukemia. In the final analytical phase, the findings obtained in the theoretical and field phases were integrated to confirm the details of resilience processes in children with leukemia based on evidence and develop a new resilience model.

Results: Through interviews, 273 codes, 45 labels, 15 sub-categories, and 6 categories were extracted. In children with leukemia, resilience comprised processes by which protective factors control the senses of disgust and fear associated with stressors and vulnerability factors, and induced resilient responses, such as self-denial, proactive preparedness, coping, and emotional adjustments (in this order), leading to adaptation at the time of the study. Among these responses, self-denial and proactive preparedness were promoted by protective factors, while emotional adjustments were made through coping, consequently controlling the senses of disgust and fear and developing an accepting attitude toward unwillingness. This had helped the children achieve adaptation in the absence of post-traumatic stress disorder by the time of the study.

Conclusion: This study clarified the details of resilience processes in children with leukemia, including their resilient responses promoted by protective factors, and confirmed the usefulness of a new resilience model for such children.
\end{abstract}

\section{Introduction}

Children with leukemia suffer from long-term distress due to repeated examinations and treatments, such as bone marrow aspirations, lumbar punctures, and intraspinal injections. Stuber el al. [1-3] suggested that it may be possible to examine socio-psychological issues in children who have undergone bone marrow transplantation within the framework of post-traumatic stress disorder (PTSD), and that facing a severe disease and undergoing invasive treatment may be a traumatic experience for children. In line with this, repeated examinations and treatments are also likely to cause severe distress corresponding to type II trauma in children with leukemia, involving the senses of disgust and fear, and possibly leading to PTSD. On the other hand, in the studies on PTSD in pediatric cancer patients conducted by Bulter et al. [4] and Kazak et al. [5], the proportion of those completely meeting the PTSD criteria was limited, even when some symptoms of post-traumatic stress disorder were self-reported.

Resilience is being increasingly focused on as a basis for understanding such children. It is defined as the ability to appropriately adapt despite a threatening situation and the outcome of such adaptation, and also as an important concept for positive health. Furthermore, enabling researchers to develop effective intervention methods addressing stress responses by examining the characteristics of resilient individuals and related factors, it is also drawing increased attention as a useful concept in nursing.

As the phase of resilience (successful adaptation process, ability, and outcome) focused on varies among researchers, literature reviews, including conceptual classification, are needed when conducting resilience studies involving children with leukemia. Therefore, with the aim of developing effective support techniques to prevent trauma from leading to PTSD in such children, the hybrid model of concept development (HMCD) (Schwartz-Barcott \& Kim, 2000) [6], developed to sophisticate concepts, was used to confirm the details of resilience processes in children with leukemia based on evidence, and to develop a new resilience model.

\section{Methods}

The concept analysis of resilience was performed according to the hybrid model of concept development (HMCD), which was developed by Schwartz-Barcott \& Kim in 2000 to sophisticate concepts [6]. This model combines theoretical and empirical techniques, with a view to promoting the development of concepts, and consists of 3 phases integrating inductive and deductive/analytical approaches: theoretical, fieldwork, and final analytical (Figure 1). In the present study, a literature review on resilience of children with leukemia was conducted in the theoretical phase. In the fieldwork phase, semi-structured interviews regarding examination and treatment

"Corresponding Author: Dr. Ikuko Sobue, Division of Nursing Science Graduate School of Biomedical \& Health Sciences, Hiroshima University, 1-23, Kasumi, Minami-ku, Hiroshima 734-8553, Japan, Tel: +81-82-257-5370, Fax: +81-82-257-5374; E-mail: sobue@hiroshima-u.ac.jp

Citation: Nakazawa K, Sobue I (2015) Resilience Processes in Children with Leukemia: Developing a New Resilience Model. Int J Nurs Clin Pract 2: 118. doi: http://dx.doi.org/10.15344/2394-4978/2015/118

Copyright: ( $) 2015$ Sobue et al. This is an open-access article distributed under the terms of the Creative Commons Attribution License, which permits unrestricted use, distribution, and reproduction in any medium, provided the original author and source are credited. 
were conducted to clarify the details of resilience. Lastly, in the final analytical phase, the findings obtained in the theoretical and field phases were integrated to confirm the details of resilience of children with leukemia based on evidence and develop a new resilience model.

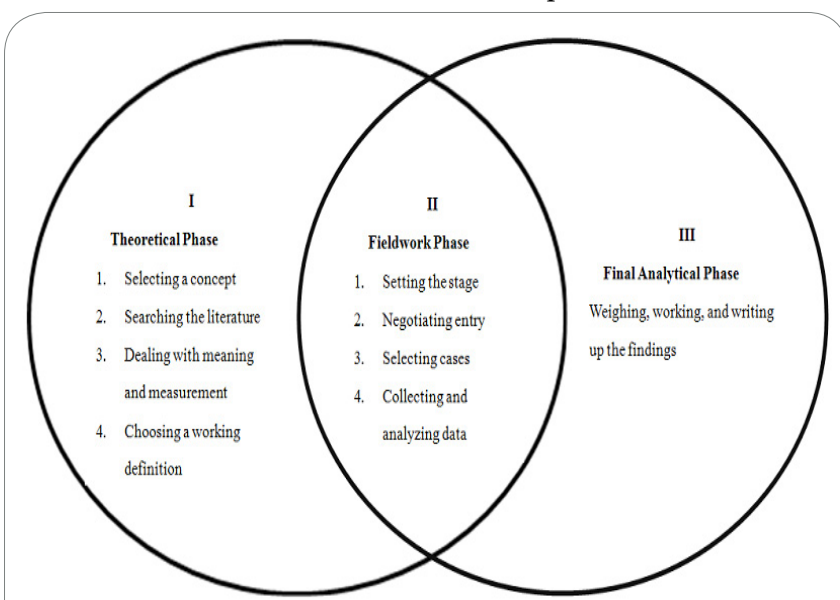

Figure 1: The hybrid model of concept development [6].

A computerised literature search was performed from January 2001 to August 2006 of Medline, CINAHL and Igaku Chuo Zasshi (ICHUSHI). The search terms were: resilience, leukemia, and pediatric or child.

Only two articles were found in CHINAL [7] and ICHUSHI [8]. Because it was difficult to find articles directly related to the purpose of this study, a manual search of the reference lists was conducted to identify the articles that included the following words: resilience and leukemia or pediatric or child.

\section{Theoretical phase}

Up to the present, resilience has mostly been examined in theoretical studies, and empirical studies focusing on it have been limited to measurement of the personality traits of resilient individuals and related factors.

Masten et al. defined resilience as the ability to appropriately adapt and the outcome of such adaptation, and described it as overcoming difficulties, abilities maintained in the presence of stress, and recovery from trauma [9]. Resilience allows two different focuses: abilities and successful outcomes as a resilience-related trait; and the process of adaptation.

Resilience is promoted through dynamic interactions between abilities and environmental factors that have been regarded as resilience-related traits, considering that both are helpful for overcoming difficult situations and risks. Protective factors are traits promoting resilience and functioning as learning experiences. In diverse and difficult situations due to poverty, abuse, disease, or other causes during two developmental stages-infancy and adulthood- the ability to recognize, address, and redefine stress is a personality trait functioning as a protective factor, and it is associated with self-control, esteem, and efficacy. Family traits are related to strong family bonds, while social traits are related to supporters other than family members, supportive relationships, and support itself [10-18]. Protective factors play an important role in helping individuals overcome risks and direct themselves toward positive perspectives as media, and integrate four functions: reducing the impact of risks; avoiding negative chain reactions (vicious circles); enhancing and maintaining senses of selfesteem and efficacy; and creating opportunities to grow [19].
Rutter regarded resilience as a process $[19,20]$, and Luthar et al. defined it as a dynamic process to achieve positive adaptation despite severely adverse contexts [21]. In short, resilience is a dynamic process, and adaptation is under the influence of interactions between protective and risk factors in each situation [19]; however, up to the present, the influences of protective factors on stressors and vulnerability factors, as well as adaptation, in resilience processes have been examined only in theoretical studies.

In a resilience model for adolescent cancer patients developed by Woodgate in 1999, resilience is regarded as a set of processes to adapt, and Rutter's and Garmezy's theories are adopted as theoretical pillars. It consists of stressors, protective and vulnerability factors, processes, and outcomes (maladaptation or adaptation) [22, 23] (Figure 2). Stressors are specific events or situations (such as losses, events requiring social adaptation, and physical injuries) inducing such patients' emotional responses [24]. Vulnerability factors promote their negative responses or vulnerability to stressors, leading to maladaptation [19]. In children with cancer, stressors and vulnerability factors increase risks and the incidence of dysfunction. In contrast, protective factors control their negative responses to stressors and vulnerability factors, and guide them toward improvement or a shift from maladaptation to adaptation [20]. As all of these components are interrelated, Woodgate's resilience model comprises a continuum between adaptation and maladaptation [25]. Although it regards resilience as a set of processes, their details are limited to the contents suggested by Rutter.

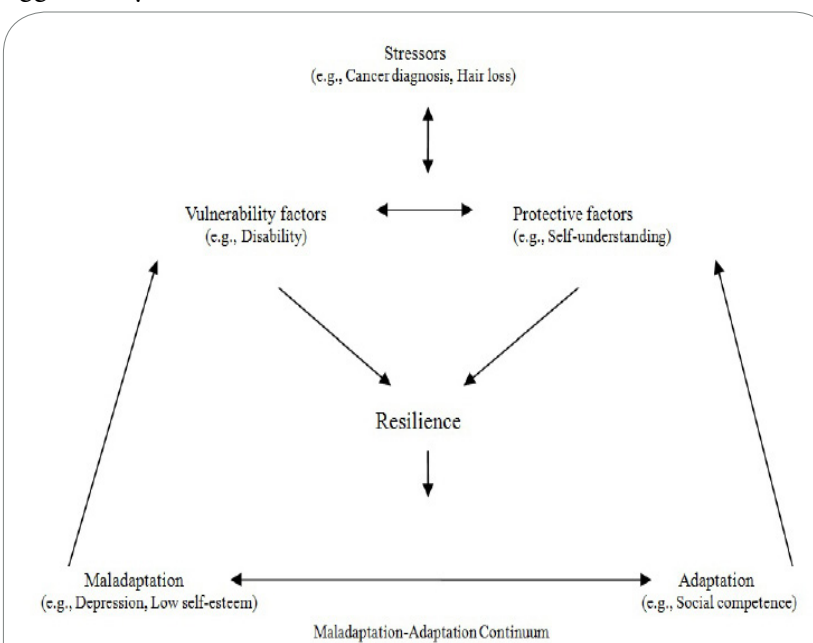

Figure 2: Resiliency model as applied to adolescent cancer patients [22].

To the authors' knowledge, resilience processes were previously examined exclusively in theoretical studies, without fully clarifying their details. In order to prevent PTSD in children with leukemia, it may be essential to further develop resilience theories. It may also be necessary to examine resilient responses and coping supported by protective factors as processes to achieve resilient personality traits or outcomes (adaptation).

\section{Fieldwork phase}

\section{Objective}

To clarify resilience processes in children with leukemia who repeatedly undergo examination and treatment, with the aim of providing a basis for the prevention of PTSD in such children. 


\begin{tabular}{|c|c|c|c|c|c|c|c|c|c|c|}
\hline Case & Sex & Age & $\begin{array}{l}\text { Type of } \\
\text { disease }\end{array}$ & Recurrence & $\begin{array}{l}\text { Age at } \\
\text { onset }\end{array}$ & $\begin{array}{l}\text { Number of } \\
\text { bone marrow } \\
\text { aspirations }\end{array}$ & $\begin{array}{l}\text { Number } \\
\text { of lumbar } \\
\text { punctures } \\
\text { (including } \\
\text { intraspinal } \\
\text { injections) }\end{array}$ & $\begin{array}{l}\text { Scheduled } \\
\text { intraspinal } \\
\text { injections }\end{array}$ & $\begin{array}{l}\text { Type of } \\
\text { treatment }\end{array}$ & $\begin{array}{l}\text { Bone marrow } \\
\text { aspiration/lumbar } \\
\text { puncture/anesthesia }\end{array}$ \\
\hline A & Female & 15 & AML & None & 14 & 5 & 4 & None & Outpatient & Performed \\
\hline B & Male & 12 & ALL & None & 9 & 6 & 10 & None & Outpatient & Performed \\
\hline $\mathrm{C}$ & Male & 12 & ALL & $\begin{array}{l}\text { Once (when } \\
\text { aged } 10 \text { ) }\end{array}$ & 5 & 7 & 20 & None & Outpatient & $\begin{array}{l}\text { Performed at onset, } \\
\text { not performed on } \\
\text { recurrence }\end{array}$ \\
\hline $\mathrm{D}$ & Male & 12 & ALL & None & 7 & 7 & 18 & None & Outpatient & Not performed \\
\hline $\mathrm{E}$ & Female & 11 & ALL & None & 10 & 6 & 9 & Scheduled & Outpatient & Performed \\
\hline $\mathrm{F}$ & Male & 11 & ALL & None & 10 & 3 & 8 & None & Inpatient & $\begin{array}{l}\text { Performed from the } \\
\text { second session }\end{array}$ \\
\hline G & Male & 9 & AML & None & 8 & 3 & 4 & None & Outpatient & $\begin{array}{l}\text { Performed only } \\
\text { during the first } \\
\text { session }\end{array}$ \\
\hline
\end{tabular}

Table 1: The Children's Demographic Variables.

AML: Acute myeloid leukemia, ALL: Acute lymphoid leukemia.

\section{Subjects}

Seven children with leukemia ( 5 males and 2 females aged $11.7 \pm 1.80$ years), who had been treated on Ward B of Hospital A between September and October 2006, were studied (Table 1). Among those referred by the doctor in charge in consideration of their confidence in his explanations, expectations for healing, and the absence of lifethreatening conditions, the following pediatric patients were included: those currently undergoing maintenance therapy in the remission phase or under observation after the termination of treatment, and who had been provided with explanations regarding the disease or pathological condition; those aged 9 or over; and those in whom type II trauma-specific symptoms (such as escapism or self-mutilation due to painful treatment) were observed. Based on Piaget's theory of cognitive development, children aged 9 or over are considered able to develop theoretical thoughts, to view the disease using their knowledge, and to verbally express their emotions and feelings [26]. In Cases B, C, E, F, and G, escapism, such as making a detour on the passageway toward the treatment room to avoid painful examination or treatment during hospitalization, or taking 30 minutes or more to enter the treatment room, was observed. In Cases D and F, selfmutilation, such as repetitive picking of the skin of the fingertips or heels to an extent where bleeding was caused, was observed when waiting for examination or treatment after a notification.

Semi-structured interviews were conducted in a closed, single room to protect the privacy of the children, who were accompanied by their parents. The duration of each session was 30 to 60 minutes.

\section{Ethical considerations}

With the permission of the Nursing Department of the study hospital, explanations outlining the study were provided to the doctor in charge and chief nurse on Ward B to obtain their approval. After obtaining the parents' informed consent, and in their presence, the children were provided with oral and written explanations regarding the study objective, methods, data use limited to research purposes, voluntary participation, unconditional refusal and withdrawal, maintenance of anonymity, personal information protection, recording during interview sessions, and appropriate data destruction. Written informed assent and consent forms were received from the children and their parents, respectively.

\section{Analysis}

In each case, recorded narratives were repeatedly read and classified for encoding, without changing their semantic contents. Similar contents were labeled, related to corresponding events, and classified into sub-categories. Subsequently, based on the similarity among the 7 cases, sub-categories and categories were created.

\section{Final analytical phase}

The final step was to integrate the findings of the previous studies in the theoretical phase, and the consequences of the interviews in the fieldwork phase. A new resilience model was constructed by including the process of resilience.

\section{Results}

\section{Fieldwork phase}

Through interviews, 273 codes, 45 labels, 15 sub-categories, and the following 6 categories were extracted (Table 2): [stressors], [vulnerability factors], [stress responses], [protective factors], [resilient responses], and [adaptation observed in the absence of PTSD at the time of the study]. In the following sections, various symbols are used to describe: categories: [ ], sub-categories: \{\} , labels: $<>$, the children's narratives: "', and supplementary items: ( ).

\section{Characteristics of narratives and associations among categories}

\section{(1)[Stressors], [vulnerability factors], and [stress responses]}

In all cases, the \{sense of disgust $\}$ and \{sense of fear\} intensified as [stress responses] to repeated examinations and treatments. As [stressors] (factors inevitably involved in such examinations and treatments, intensifying the senses of disgust and fear), (examinationand treatment-related distress\}, \{side effects of examination and treatment $\}$, and $\{$ examination-and treatment-relatedlimitationsindaily life activities\} were extracted. \{Examination- and treatment-related 
Citation: Nakazawa K, Sobue I (2015) Resilience Processes in Children with Leukemia: Developing a New Resilience Model. Int J Nurs Clin Pract 2: 118. doi: http://dx.doi.org/10.15344/2394-4978/2015/118

\begin{tabular}{|c|c|c|}
\hline Category & Sub-category & Label \\
\hline \multirow[t]{12}{*}{ Stressors } & \multirow[t]{8}{*}{ Examination- and treatment-related distress } & Needle-stick pain \\
\hline & & Invisible site of puncture \\
\hline & & Pain without anesthesia \\
\hline & & Pain due to inappropriate puncture \\
\hline & & Being immobilized during the procedure \\
\hline & & $\begin{array}{l}\text { The doctor wearing a gown, performing the gown } \\
\text { technique }\end{array}$ \\
\hline & & Odors in the treatment room \\
\hline & & Repetition \\
\hline & Vulnerability associated with family relationships & Nausea and vomiting after intraspinal injection \\
\hline & \multirow{3}{*}{$\begin{array}{l}\text { Examination- and treatment-related limitations in } \\
\text { daily life activities }\end{array}$} & Bedrest after examination \\
\hline & & Fasting \\
\hline & & Depressive feelings when waiting for examination \\
\hline \multirow[t]{5}{*}{ Vulnerability factors } & Vulnerability associated with family relationships & Encouragement by other family members \\
\hline & \multirow{4}{*}{$\begin{array}{l}\text { Vulnerability associated with medical or nursing } \\
\text { services }\end{array}$} & Repeated encouragement \\
\hline & & Explanations on the previous day \\
\hline & & Detailed explanations \\
\hline & & Side effects of anesthesia \\
\hline \multirow[t]{8}{*}{ Stress responses } & \multirow[t]{5}{*}{ Sense of disgust } & Hatred toward its name, procedure, and everything \\
\hline & & Disgusting to the point of tears \\
\hline & & 100 times worse than blood sampling and drips \\
\hline & & Never wanting to undergo it anymore \\
\hline & & Hatred to the point of attempting to escape \\
\hline & \multirow[t]{3}{*}{ Sense of fear } & Extremely frightening \\
\hline & & Unbearable fear that psychologically affects him/her \\
\hline & & Need for family to enter the "scary" treatment room \\
\hline \multirow[t]{9}{*}{ Protective factors } & \multirow[t]{3}{*}{ Personality traits } & Future-oriented thoughts \\
\hline & & Positive thoughts \\
\hline & & Self-respect \\
\hline & \multirow{3}{*}{ Support from other family members } & Rewards \\
\hline & & Being accompanied by family \\
\hline & & $\begin{array}{l}\text { Avoiding examination- and treatment-related issues } \\
\text { during conversations }\end{array}$ \\
\hline & \multirow[t]{3}{*}{ Support from medical and nursing staff } & Anesthesia \\
\hline & & Explanations on the previous day \\
\hline & & Ordinary topics \\
\hline \multirow[t]{9}{*}{ Resilient responses } & Self-denial & Accepting behavior \\
\hline & Proactive preparedness & Motivation \\
\hline & \multirow[t]{4}{*}{ Coping } & Games \\
\hline & & Awareness of falling into unconsciousness \\
\hline & & Psychological preparations \\
\hline & & $\begin{array}{l}\text { Concentrating on diversions, avoiding thinking about } \\
\text { unpleasant issues }\end{array}$ \\
\hline & \multirow[t]{3}{*}{ Emotional adjustments } & Diversions \\
\hline & & Less painful \\
\hline & & Sense of security \\
\hline \multirow{2}{*}{$\begin{array}{l}\text { Adaptation observed in the absence of PTSD at the } \\
\text { time of the study }\end{array}$} & \multirow[t]{2}{*}{ No re-experience } & Not remembering \\
\hline & & Having overcome treatment \\
\hline
\end{tabular}

Table 2: Categories and Sub-categories. 
distress\} consisted of 8 labels, including <pain without anesthesia $>$, while \{side effects of examination and treatment $\}$ comprised $<$ nausea and vomiting after intraspinal injection $>$. Furthermore, \{examinationand treatment-related limitations in daily life activities\} consisted of 3 labels, including <bed rest after examination>. As [vulnerability factors] (those not inevitably involved in examination or treatment, but intensifying the senses of disgust and fear), \{vulnerability associated with family relationships\} and \{vulnerability associated with medical or nursing services\} were extracted; the former comprised <encouragement by other family members $>$, while the latter consisted of 4 labels, including <repeated encouragement $>$ and $<$ side effects of anesthesia $>$, revealing that frequent encouragement by other family members and medical professionals disgusted the children, intensifying their senses of disgust and fear.

\section{- [Stress responses] associated with [stressors]}

\{Sense of disgust\} due to \{examination- and treatment-related distress\}:

"I don't want any more injections in my lower back. I will die if I have to have another one." $(C)$

"What I hate the most is the pain when they stick a needle in. Compared to intraspinal injections, blood sampling and drips were 100 times less painful."(D)

"I hate both intraspinal injections and bone marrow aspirations, because they are so painful. They really disgust me whenever they are repeated." $(F)$

\{Sense of fear\} due to \{examination- and treatment-related distress\}:

"I used to escape when they told me to come, because I didn't want to enter the treatment room. It was scary." $(G)$

\{Sense of disgust\} due to the \{side effects of examination and treatment\}:

"I didn't like vomiting and all the other adverse effects after injections in my lower back." $(G)$

\{Sense of disgust\} due to \{examination- and treatment-related limitations in daily life activities\}:

"What I hated was that I couldn't eat right away."(B)

\section{- [Stress responses] associated with [vulnerability factors]}

\{Sense of disgust\} due to \{vulnerability associated with family relationships\}:

"They encourage me repeatedly, including my family. I'm about to say, 'OK, I will do my best, but I am the person who has to hold on. Not you'.'(A)

\{Sense of fear\} due to \{vulnerability associated with medical or nursing services\}:

"I prefer not listening to their explanations, because they are scary."(A)

"Detailed explanations scare me even more. It's already disgusting enough, so I don't want to imagine it until I actually undergo it. I would faint if they showed me a needle during an explanation."(C)

\{Sense of disgust $\}$ due to \{vulnerability associated with medical or nursing services\}:

"I hate anesthesia. It haunts my dreams. It's like a nightmare with zombies. Some zombies have 3 eyes. Horrible ... I bet you would also hate it." $(F)$

"It (the explanation of examination) is important. That's true. But it is enough to explain it only once. Repeated explanations exhaust me."(A) "I remember those painful times when they said to me "You have done your best' over and over again."( $C)$

\section{(2) [Protective factors] and [resilient responses]}

As [protective factors], controlling the \{sense of disgust $\}$ and \{sense of fear\} associated with [stressors], and [vulnerability factors], \{personality traits\}, \{support from other family members\}, and \{support from medical and nursing staff $\}$ were extracted. \{Personality traits\} consisted of the following 3 labels: <future-oriented thoughts $>$, $<$ positive thoughts $>$, and $<$ self-respect $>$. \{Support from other family members\} consisted of 3 labels, including <rewards $>$. \{Support from medical and nursing staff $\}$ also consisted of 3 labels, such as $<$ anesthesia $>$ and <explanations on the previous day $>$.

As [resilient responses], \{self-denial\}, \{proactive preparedness\}, \{coping\}, and \{emotional adjustments\} were extracted. \{Self-denial\} and \{proactive preparedness\} comprised <accepting behavior $>$ and $<$ motivation $>$, respectively, while \{coping\} consisted of 4 labels, such as $\langle$ games $>$. \{Emotional adjustments\} consisted of 3 labels, including $<$ diversions $>$.

[Protective factors] were shown to convert [stress responses] into [resilient responses]. $<$ Future-oriented thoughts $>$ contributed to the development of < accepting behavior $>$, reducing the \{sense of disgust\}. Such <accepting behavior $>$ was observed in all cases, highlighting the children's firm intention to achieve their goal - curing the disease. The 3 labels for \{personality traits\}, such as <future-oriented thoughts $>$, alleviated the senses of disgust and fear, and $<$ rewards $>$ from other family members enhanced motivation. <Being accompanied by family $>$ enhanced the sense of security. $<$ Games $>$ as a label for $\{$ coping\} were indispensable for the children to control their senses of disgust and fear by taking their mind off the treatment and overcoming their difficult situations. Similarly, some children stated that they were able to block such senses by limiting conversations to <ordinary topics>, avoiding examination- and treatment-related issues.

\section{- [Resilient responses] associated with [protective factors]}

$<$ Accepting behavior $>$ for $\{$ self-denial $\}$ based on $<$ future-oriented thoughts $>$ as a \{personality trait\}:

"I don't want to, but I have to undergo it to cure my disease and move on."(B)

"I want to finish my treatment and be discharged as soon as possible. So, I have to hold on, although it disgusts me." $(F)$

$<$ Motivation $>$ to develop \{proactive preparedness \} based on $<$ positive thoughts $>$ as a \{personality trait\}:

"I am a positive person by nature." (A)

"I can get through it until the end, thanks to my proactive and positive thoughts." $(C)$

$<$ Motivation $>$ to develop \{proactive preparedness\} based on $<$ selfrespect $>$ as a \{personality trait\}:

"I am not a small child anymore, and would feel ashamed if I behaved like that. It's disgusting, but I have to do it."(E)

"I usually complain to stall, but one day, when another boy in the same room also came along and therefore I thought that I had to behave myself as his elder, things went more smoothly. Self-respect is important."(C)

$<$ Motivation $>$ to develop \{proactive preparedness\} and $<$ rewards $>$ as \{support from other family members\}:

"They bought me a present after completing a session. This made me happy, and may also have increased my motivation."(B)

"I got a reward for trying hard during hospitalization. I tried hard, expecting such a reward." $(D)$

Enhanced <sense of security> through \{emotional adjustments\} with <being accompanied by family $>$ as \{support from other family members\}:

"I felt secure when my mother was with me."(C)

"The presence of my mother was helpful." $(G)$

$<$ Diversions $>$ for $\{$ emotional adjustments $\}$ by $<$ avoiding examinationand treatment-related issues $>$ during conversations as \{ support from 
other family members\}:

"Mother tries to relax our child, only asking him about meals and such things. Mother avoids talking about treatment during conversations."(B)

"Both mother and I never mention injections in his lower back." $(C)$

$<$ Less painful $>$ for \{emotional adjustments\} with <anesthesia $>$ as \{support from medical and nursing staff\}:

"It's still scary, but less painful now, because I don't feel pain under anesthesia." $(C)$

$<$ Psychological preparations $>$ for $\{$ coping through $<$ explanations on the previous day $>$ as \{support from medical and nursing staff\}:

"Advance explanations help me prepare myself. It is best to be explained to the day before."(B)

"I think it is appropriate for them to notify me of an injection in my lower back one day before. Previously, I would worry too much, and, immediately before, I would not be sufficiently prepared."(C)

$<$ Awareness of falling into unconsciousness $>$ for \{coping\} using $<$ anesthesia $>$ as \{support from medical and nursing staff\}:

"I think I have become skilled at enhancing the effects of anesthesia on my body. I can fall into unconsciousness with more awareness now.. When I detect that sensation, I release my mind, and just let it enter me. All I have to do is waiting while being relaxed until it takes effect, because I know that it relieves my pain." $(A)$

\section{- Process by which [resilience] promotes further [resilience]}

$<$ Motivation $>$ to develop \{proactive preparedness\} through \{selfdenial $\}$ as an <accepting behavior $>$ :

"I knew that it was inevitable for me to overcome anxiety. Nobody but myself could help me. Who else could remove such a feeling from my mind?" $(A)$

$<$ Less painful $>$ for \{emotional adjustments\} by <awareness of falling into unconsciousness $>$ for $\{$ coping $\}$

"When anesthesia takes effect, I naturally become quiet and fall asleep. It is less painful as long as I am asleep."(A)

$<$ Diversions $>$ for \{emotional adjustments\} using <games $>$ for \{coping\}:

"When they notified me of treatment, I used to play games, trying to take my mind off it. Games were helpful to change my feelings."(B)

"Games are the most effective way to refresh my mind." $(C)$

\section{(3) Process of developing [resilient responses]}

On analysis of the children's narratives, \{self-denial\}, \{proactive preparedness\}, \{coping\}, and \{emotional adjustments\} were extracted as [resilient responses] in those repeatedly undergoing examination and treatment. Through \{self-denial\}, they recognized their unwillingness to undergo examination and treatment as a traumatic event, and became more aware of the necessity of undergoing them to cure the disease and move on. In short, \{self-denial $\}$ as an accepting behavior contributed to the development of \{proactive preparedness\}, and \{emotional adjustments\} were made by \{coping\} to control the \{sense of disgust $\}$ and \{sense of fear\}. Through this process, an accepting attitude toward unwillingness was developed, leading to [adaptation observed in the absence of PTSD at the time of the study]

In fact, in Case A, such an attitude toward the unwillingness to undergo examination and treatment was observed when the child stated, "It is inevitable. I know it..." In this case, \{proactive preparedness\}, such as making efforts to achieve the goal of curing the disease, was developed through \{self-denial $\}$ and expressed in the statement that she knew that it was inevitable for her to overcome anxiety. She also stated, "I had to control my mind. That was all I could do. I needed to avoid thinking about bone marrow aspirations.
I just thought about my favorite things and kept watching my favorite $T V$ programs...," indicating that she made \{emotional adjustments\} and developed an accepting attitude toward unwillingness by such \{coping\}.

In Case B, this attitude was observed in the statement, "I didn't want to enter the treatment room, but they forced me to do it. It was inevitable." As he also stated, "I don't want to, but I have to undergo them to cure my disease and move on," he was aware of the necessity of undergoing examination and treatment, showing \{proactive preparedness\}. His statement, "When they notified me of treatment, I used to play games, trying to take my mind off it. Games were helpful to change my feelings" indicated that he controlled the \{sense of disgust \} and \{sense of fear\} by $\{$ coping and making \{emotional adjustments\}, and developed an accepting attitude toward unwillingness.

\section{(4) [Adaptation observed in the absence of PTSD at the time of the study]}

Considering that its symptoms are not necessarily or continuously manifested immediately after a traumatic event, and that it may influence children throughout their lives, PTSD was regarded as absent at the time of the study. As \{no re-experience\} was extracted, the children were considered to have appropriately adapted by that time.

\section{- $\quad$ No re-experience $\}$}

"I never see them in my dreams." $(G)$

"I don't have negative feelings anymore." (F)

"It seems that the experience of overcoming distress at the hospital has guided me in the right direction. Now I can say that it was a good experience." (C)

\section{Resilience model}

Resilience in the children with leukemia repeatedly undergoing examination and treatment was regarded as a set of processes by which \{personality traits\}, \{support from other family members\}, and \{support from medical and nursing staff\} as [protective factors] positively influenced their \{sense of disgust $\}$ and \{sense of fear\} as [stress responses] associated with [stressors] and [vulnerability factors], consequently developing [resilient responses] and leading to [adaptation observed in the absence of PTSD at the time of the study]. In such processes, \{self-denial\}, nurtured \{proactive preparedness\}, and $\{$ emotional adjustments $\}$ were made by \{coping $\}$ to achieve adaptation (Figure 3).

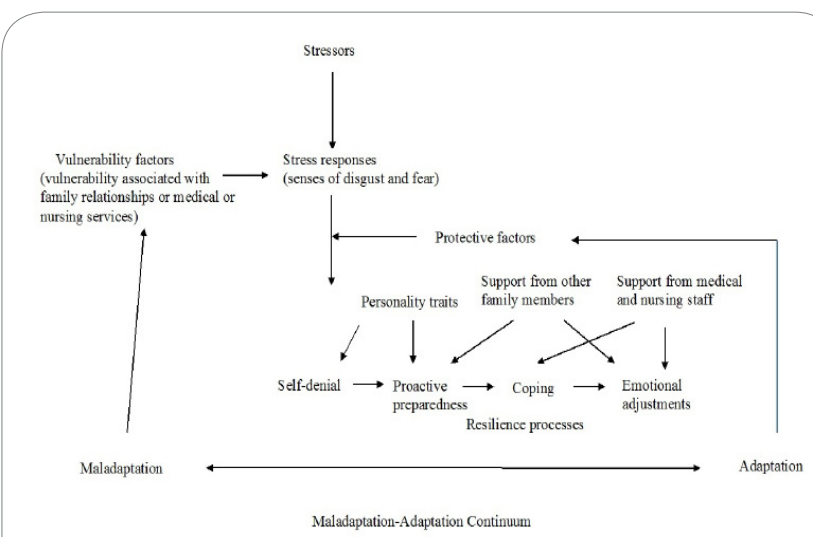

Figure 3: New resilience model as applied to children with leukemia. 


\section{Discussion}

\section{Final analytical phase}

The children's $\{$ sense of disgust $\}$ and $\{$ sense of fear $\}$ as stress responses associated with stressors and vulnerability factors correspond to a DSM-IV-TR criterion for PTSD -exposure to traumatic events [27]; however, as none of them showed its symptoms, such as reexperience of traumatic events, continuous avoidance of traumarelated stimuli, numbing of general responsiveness, or persistent hyper-arousal, PTSD was regarded as absent. The findings obtained in the theoretical phase and the results of comprehensive analysis in the fieldwork phase confirmed the usefulness of the developed resilience model comprising stressors, vulnerability and protective factors, and processes.

As novel findings, it was demonstrated that: protective factors convert stress responses into resilient responses; the latter responses comprise 4 processes: \{self-denial\}, \{proactive preparedness\}, \{coping\}, and \{emotional adjustments\} (in this order); and that the children had achieved adaptation by the time of the study. For example, as observed in the statement, "I want to finish my treatment and be discharged as soon as possible. So, I have to hold on to this, although it disgusts me," <future-oriented thoughts> as a protective factor may be regarded as a consequence of a shift from the sense of disgust to self-denial. The children were unwilling to undergo examination and treatment, but were aware of the necessity or benefit of undergoing them to cure the disease; in short, \{self-denial\} may have contributed to the development of \{proactive preparedness\}. Furthermore, stated as "I tried hard, expecting such a reward" \{coping\} and \{emotional adjustments\} supported \{self-denial\} and \{proactive preparedness\}, and resilient responses promoted resilience. Consequently, during the interview, one of the children stated, "It seems that the experience of overcoming distress in the hospital has guided me in the right direction. Now I can say that it was a good experience", indicating his stressrelated growth.

As important psychological traits commonly observed in resilience, 'future-oriented positive thoughts', 'emotional adjustments', and 'diverse interests' have been reported [28-30]. The \{proactive preparedness\} observed in the present study is similar to 'futureoriented positive thoughts', and \{coping\} and \{emotional adjustments\} may correspond to 'emotional adjustments' [31]. As these responses are psychological traits achieved through the process of adaptation in a stressful situation, they naturally correspond to psychological traits common among resilient individuals. Based on this, \{self-denial\} may be a novel response, considering that it has not been reported in any previous study, to the authors' knowledge.

In the 'Diary of Rinaldo', Goethe noted that self-denial is an unavoidable choice for humans [32], while Okazaki defined it as abnegating lusts or concentrating and making efforts to achieve goals, rather than passively or quietly relinquishing desires disturbing such achievement [33]. Self-denial is not an ideological product, but is wisdom achieved through coping with distress [34]. The statement, "I don't want to, but I have to undergo it to cure my disease and move on," observed in the present study, suggested that the children may have defined their senses of disgust and fear as factors disturbing their goal achievement-making efforts to appropriately undergo examination and treatment and cure the disease. Similarly, the statements "Nobody but myself can help me" and "I will do my best" may be regarded as responses leading to the self-denial of unwillingness and more active attitudes; in short, \{self-denial\} may be a resilient response contributing to the development of \{proactive preparedness\}.
Although \{self-denial\} was nurtured by \{personality traits\} in the present study, it may be essential to examine it with the other protective factors, using exploratory methods, as it may be a response playing an important role in the initial stages toward resilience.

\section{Clinical application}

Protective factors revealed the details of preparation that help pediatric patients, and were shown to enhance their ability to cope with difficult situations and acquire strength to lead their lives. For such preparation, the children regarded the explanation of examination or treatment on the previous day as important, but stated, "Detailed explanations scare me even more," "Repeated encouragement is not needed," or "I find ordinary topics more comfortable." These protective factors supported the process of resilience from \{self-denial\} to \{emotional adjustments\}. For children with leukemia repeatedly undergoing examination and treatment, it was crucial to avoid thinking about examination or treatment as part of the preparation for the avoidance of fear or disgust. Games were an indispensable instrument for them to control their senses of disgust and fear and maintain \{self-denial\} and \{proactive preparedness\}, by changing their feelings and avoiding thinking about treatment. Weeks \& Kagan reported that such a strategy - avoiding thinking about treatmentincreases the strength of children with cancer, who face uncertainty during treatment [35].

On the other hand, repeated encouragement by other family members or medical professionals and detailed explanations were shown to be vulnerability factors intensifying the senses of disgust and fear due to examination and treatment. In some cases, the side effects of anesthesia also intensified such senses.

Based on these findings, nurses should improve their skills to differentiate protective and risk factors and assess the preparedness levels of children with leukemia. It may also be necessary to improve the quality of care, with a view to promoting resilience in pediatric patients by adopting preventive measures against risk factors and effectively using protective factors.

\section{Study limitations and future perspectives}

Up to the present, resilience has been exclusively examined in theoretical studies even in Western countries leading in this area, and the majority of empirical studies focused on its protective factors and the characteristics of resilient individuals, generating findings that are insufficient to examine and develop resilience processes. Considering this situation, in the present study, a new resilience model was developed and its usefulness was examined, based on the hybrid model of concept development.

The study has the following limitations: the number of subjects was limited to 7; the absence of PTSD was not confirmed by doctors; the nurse who cared for the children also conducted interviews; and there was no other researcher to conduct observation as a third party. As preparation markedly influences resilience in pediatric patients who repeatedly undergo examination and treatment, it may be necessary to conduct further studies, adopting appropriate approaches to obtain reliable data, such as setting stricter inclusion criteria and expanding the contents of interviews in consideration of the developmental stage.

\section{Conclusion}

To confirm the usefulness of a resilience model for children with leukemia, semi-structured interviews were conducted with 7 children 
with leukemia who had repeatedly undergone examination and treatment, using the hybrid model of concept development.

In such children, resilience was shown to be a set of processes by which the $\{$ sense of disgust $\}$ and $\{$ sense of fear $\}$ as [stress responses] associated with [stressors] and [vulnerability factors] were controlled by \{personality traits\}, \{support from other family members\}, and \{support from medical and nursing staff $\}$ as [protective factors] to develop [resilient responses], leading to [adaptation observed in the absence of PTSD at the time of the study]. Their [resilient responses] were shown to be part of the process of adaptation, by which \{proactive preparedness\} developed through \{self-denial\}, and \{emotional adjustments\} were made by \{coping\} to achieve adaptation. Also, when explaining resilient responses promoted by protective factors, this resilience model may be useful.

\section{Competing Interests}

The authors declare that they have no competing interests.

\section{Author Contributions}

Kyoko Nakazawa and Ikuko Sobue conceptualized and designed the study, and designed the data collection; Kyoko Nakazawa were responsible for the acquisition of data and the analyses; Ikuko Sobue supervised the data analyses; Kyoko Nakazawa and Ikuko Sobue completed the manuscript.

\section{Acknowledgements}

We thank the children and their families who participated in this study willingly, and talked about their experience. In addition, we thank the doctor and nurses who cooperated with this study.

\section{References}

1. Stuber ML, Nader K, Yasuda P, Pynoos RS, Cohen S (1991) Stress responses after pediatric bone marrow transplantation: preliminary results of a prospective longitudinal study. J Am Acad Child Adolesc Psychiatry 30: 952-957.

2. Stuber ML, Nader KO (1995) Psychiatric sequelae in adolescent bone marrow transplantation survivors : implications for psychotherapy. J Psychother Pract Res 4: 30-42.

3. Stuber ML, Kazak AE, Meeske K, Barakat L (1998) Is posttraumatic stress a viable model for understanding responses to childhood cancer? Child Adolesc Psychiatr Clin N Am. 7: 169-182.

4. Butler RW, Rizzi LP, Handwerger BA (1996) Brief report: the assessment of posttraumatic stress disorder in pediatric cancer patients and survivors. $J$ Pediatr Psychol 21: 499-504.

5. Kazak AE, Alderfer M, Rourke MT, Simms S, Streisand R, et al. (2004) Posttraumatic stress disorder (PTSD) and posttraumatic stress symptoms (PTSS) in families of adolescent childhood cancer survivors. J Pediatr Psychol 29: 211-219.

6. Schwartz-Barcott D, Kim HS (2000) An expansion and elaboration of the hybrid model of concept development. In: Rodgers BL, Knafl KA (Eds.) Concept development in nursing: Foundations, techniques and applications, (2nd Ed) Sanders, USA, pp. 129-159.

7. Brokstein RT, Cohen SO, Walco GA (2002) STARBRIGHT World and psychological adjustment in children with cancer: A clinical series. Children's Health Care 31: 29-45.

8. Kobayashi M, Matsubara Y, Hiraga K, Hara M, Hamamoto K, et al. (2002) Resilience in Children with Hematologic/Oncologic Diseases. Effects of Hospitalization, the Relationship with Parents, and Patients' Ages. The Japanese Journal of Pediatric Hematology 16: 129-134.

9. Masten AS, Best KM, Garmezy N (1990) Resilience and development: Contributions from the study of children who overcame adversity. Dev Psychopathol 2: 425-444.

10. Garmezy N (1985) Stress-resistant children: The search for protective factors. In Stevenson JE (Ed.) Recent Research in Developmental Psychopathology. Pergamon Press, England, pp. 213-233.
11. Garmezy N (1987) Stress, competence, and development: continuities in the study of schizophrenic adults, children vulnerable to psychopathology, and the search for stress-resistant children. Am J Orthopsychiatry 57: 159174.

12. Garmezy N (1993) Children in poverty: resilience despite risk. Psychiatry 56: 127-136.

13. Beardslee WR, Podorefsky D (1988) Resilient adolescents whose parents have serious affective and other psychiatric disorders: importance of selfunderstanding and relationships. Am J Psychiatry 145: 63-69.

14. Werner EE (2000) Protective factors and individual resilience. In: Shonkoff JP, Meisels SJ (Eds.) Handbook of Early Childhood Intervention, (2nd Ed) Cambridge University Press, USA, pp. 115-132.

15. Rechner M (1990) Adolescents with cancer: getting on with life. J Pediatr Oncol Nurs 7: 139-144.

16. Enskar K, Carlsson M, Golsater M, Hamrin, E (1997) Symptom distress and life situation in adolescents with cancer. Cancer Nurs 20: 23-33.

17. Jacelon CS (1997) The trait and process of resilience. J Adv Nurs 25: 123129.

18. Rabkin JG, Remien R, Williams JB, Katoff $L$ (1993) Resilience in adversity among long-term survivors of AIDS. Psychiatr Serv 44: 162-167.

19. Rutter M (1987) Psychosocial resilience and protective mechanisms. Am J Orthopsychiatry 57: 316-331.

20. Rutter M (1985) Resilience in the face of adversity. Protective factors and resistance to psychiatric disorder. Br J Psychiatry 147: 598-611.

21. Luthar SS, Cicchetti D, Becker B (2000) The construct of resilience: a critical evaluation and guidelines for future work. Child Dev 71: 543-562.

22. Woodgate RL (1999) Conceptual understanding of resilience in the adolescent with cancer: Part I. J Pediatr Oncol Nurs 16: 35-43.

23. Woodgate $\mathrm{RL}$ (1999) A review of the literature on resilience in the adolescent with cancer: Part II. J Pediatr Oncol Nurs 16: 78-89.

24. Garmezy N, Rutter M (Eds.) (1983) Stress, coping, and development in children. New York: McGraw-Hill, USA.

25. Garmezy N (1994) Reflections and commentary on risk, resilience, and development. In: Haggerty RJ, Sherrod N, Garmezy N, Rutter M (Eds.) Stress, risk, and resilience in children and adolescents: Processes, mechanisms, and interventions. Cambridge University Press, England, pp. $1-18$.

26. Piaget $J$ (1972) Problèmes de psychologie génétique: L'enfant et la réalité. Denoël/Gonthier. Haga J (trans.) (1975) Hatseitekishinrigaku: Kodomonohattatunojyoken Seishin Shobo, Japan.

27. American Psychiatric Association (2000) Diagnostic and statistical manual of mental disorders; Text revision (DSM-IV-TR). 4th ed., Washington D.C. American Psychiatric Association, USA.

28. Rutter M, Quinton D (1984) Long-term follow-up of women institutionalized in childhood: Factors promoting good functioning in adult life. $\mathrm{Br} \mathrm{J}$ Dev Psychol 2: 191-204

29. Eisenberg N, Guthrie IK, Fabes RA, Reiser M, Murphy BC, et al. (1997) The relations of regulation and emotionality to resiliency and competent social functioning in elementary school children. Child Dev 68: 295-311.

30. Wolin SJ, Wolin S (1993) Bound and determined: Growing up resilient in a troubled family. New York: Villard Press.

31. Oshio A, Nakaya M, Kaneko H, Nagamine S (2002) Development and Validation of an Adolescent Resilience Scale. Japanese Journal of Counseling science 35: 57-65.

32. Goethe JW (1829) Wilhelm Meisters Wanderjahre oder die Entsagenden. Stuttgart: Philipp Reclam jun, Germany. 460.

33. Okazaki Y (1969) Ogai and Resignation. Tokyo: Hobunkan Syutupan, Japan, 302.

34. Goethe JW (1829) Wilhelm Meisters Wanderjahre oder die Entsagenden. Stuttgart: Philipp Reclam jun. Seki T (trans.) (1968) Uiruherumu maisuteru no henrekijidai in Japanese (last volum). Tokyo, Iwanami bunko, Japan. 324.

35. Weekes DP, Kagan SH (1994) Adolescents completing cancer therapy: meaning, perception, and coping. Oncol Nurs Forum 21: 663-670. 